\title{
Decision models for better land management under cultivation
}

\author{
M. C. Cunha ${ }^{1}$, T. Leitão ${ }^{2}$, J. P. Lobo-Ferreira ${ }^{2}$ \& L. S. G. Oliveira ${ }^{2}$ \\ ${ }^{I}$ Department of Civil Engineering, University of Coimbra, IMAR, \\ Portugal \\ ${ }^{2}$ LNEC, National Laboratory for Civil Engineering, Portugal
}

\begin{abstract}
Integrated water resources management is an issue of major concern in Europe. Preoccupation with environmental matters has been dramatically increased by the growing impact of various activities, such as farming. In fact, diffuse pollution provoked by agricultural practices is among the environmental challenges for which preventive measures are needed to achieve a "good status" regarding ecological and chemical parameters. Building models to support future decisions on better policies for rural land use planning (type of crops and associated fertilizers and treatment techniques) is crucial for achieving a sustainable development. This paper presents two decision models that aim to minimize diffuse pollution induced by agricultural land use and irrigation practices.
\end{abstract}

Keywords: diffusion pollution, sustainable agriculture practices, better land use decision models.

\section{Introduction}

Diffuse pollution produced by irrigation has become a major environmental problem and much research is being done into better land use (type of crops and their fertilizers, treatment techniques and irrigation practices), taking into consideration the vulnerability and risk concepts. Multidisciplinary approaches are needed if all the issues involved in the integrated management of land and water resources are to be represented. The decisions to be implemented should be carefully defined in order to achieve sustainable agricultural land use and production practices. The Water Framework Directive establishes a legal 
framework to protect surface water and groundwater use; therefore irrigation practices face new challenges. In fact, stating that "Member States shall implement the measures necessary to prevent or limit the input of pollutants into groundwater and to prevent the deterioration of the status of all bodies of groundwater" means that a new framework must be established for irrigation planning and management procedures. Decision models can significantly contribute to the design of best irrigation and land use practices (Kumar et al. [2], Manocchi and Todisco [4], Marques et al. [5], Smout and Gorantiwar [6], Gorantiwar and Smout [1]).

This paper presents two decision models which aim to minimize diffuse pollution, which is represented here as $\mathrm{NO}_{3}$. . These models were developed under the research project POCTI/AGR/57719/2004 [3] and use the information gathered on the soil and aquifer characterization during the course of the project, as well as the results of field experiments about irrigation and land use practices.

\section{The case study}

The case study area is located in the watershed included in "Infrastructure 12" of the irrigated area of Alqueva Dam (Figure 1). The irrigated plots (P1, P2, P3, P4 and P5) are depicted in the same figure.

A numerical model for simulating groundwater flow has been developed, and it allowed the identification of flow direction to the small rivers (southeast to northeast) as illustrated by Figure 2 and detailed in Figure 3 and Figure 4, which show the variation of the piezometric levels between $80 \mathrm{~m}$ and $100 \mathrm{~m}$.

The use of (http://www.modflow.com/modpath/modpath.html) MODPATH software made it possible to visualize particle movement, as displayed in Figure 5, which confirms the previous conclusions in terms of flow directions.

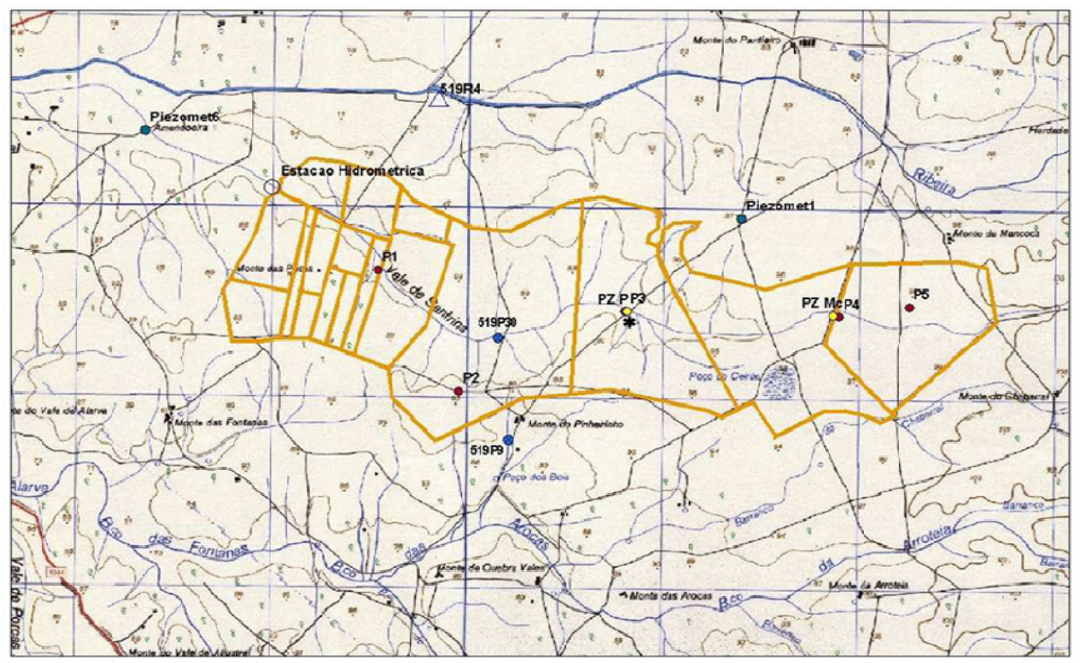

Figure 1: Case study area. 


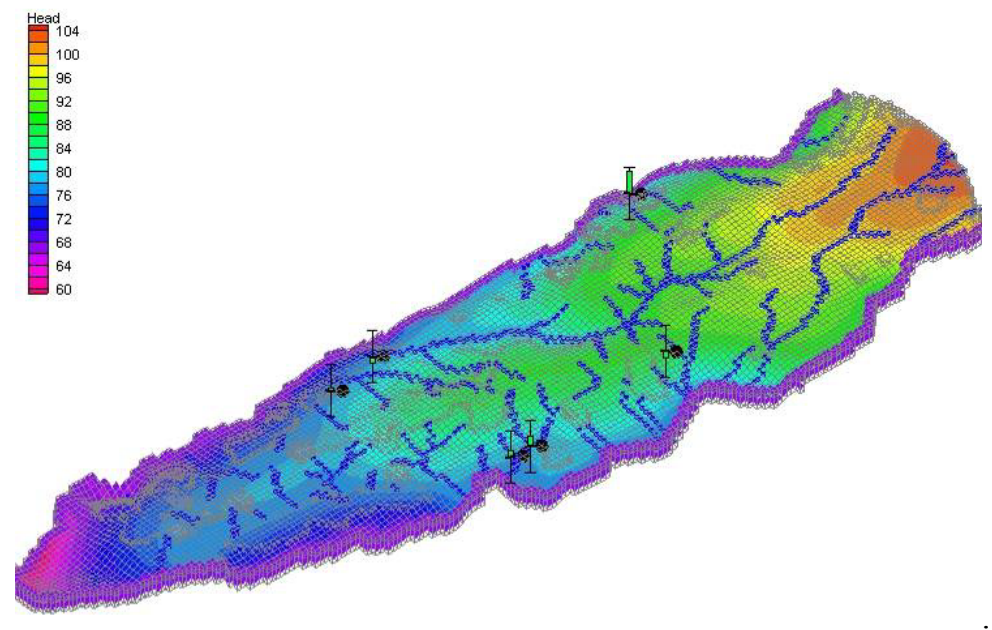

Figure 2: $\quad$ Piezometric levels.

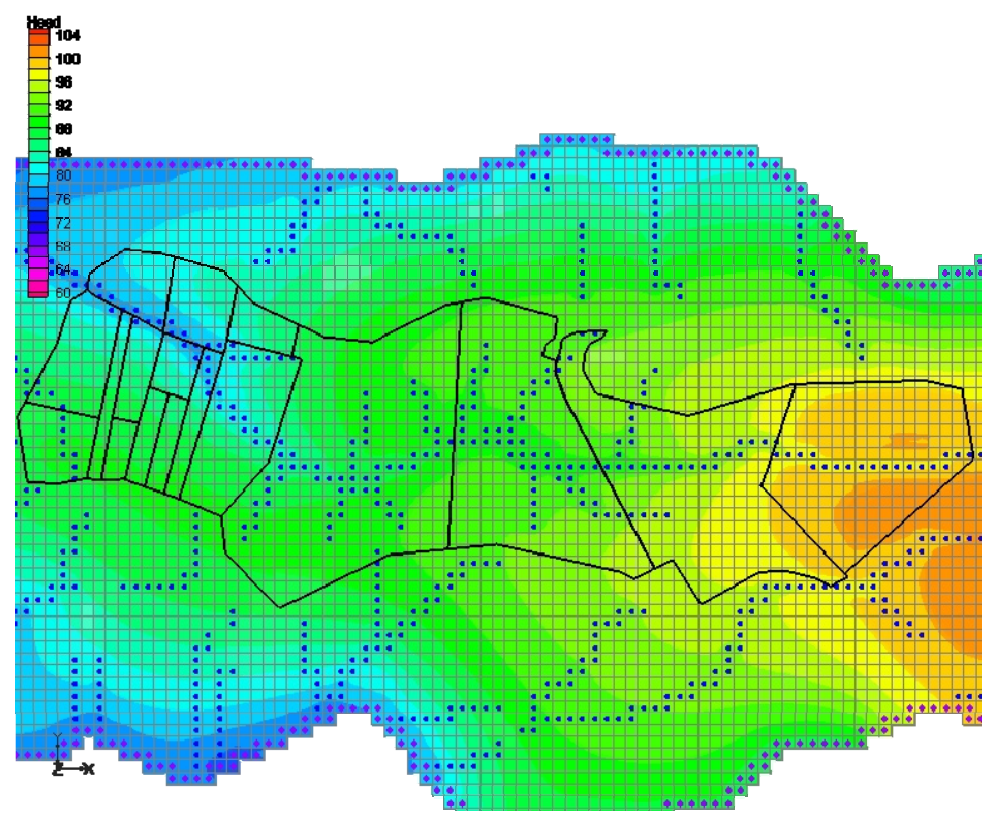

Figure 3: Detailed representation of the piezometric levels. 


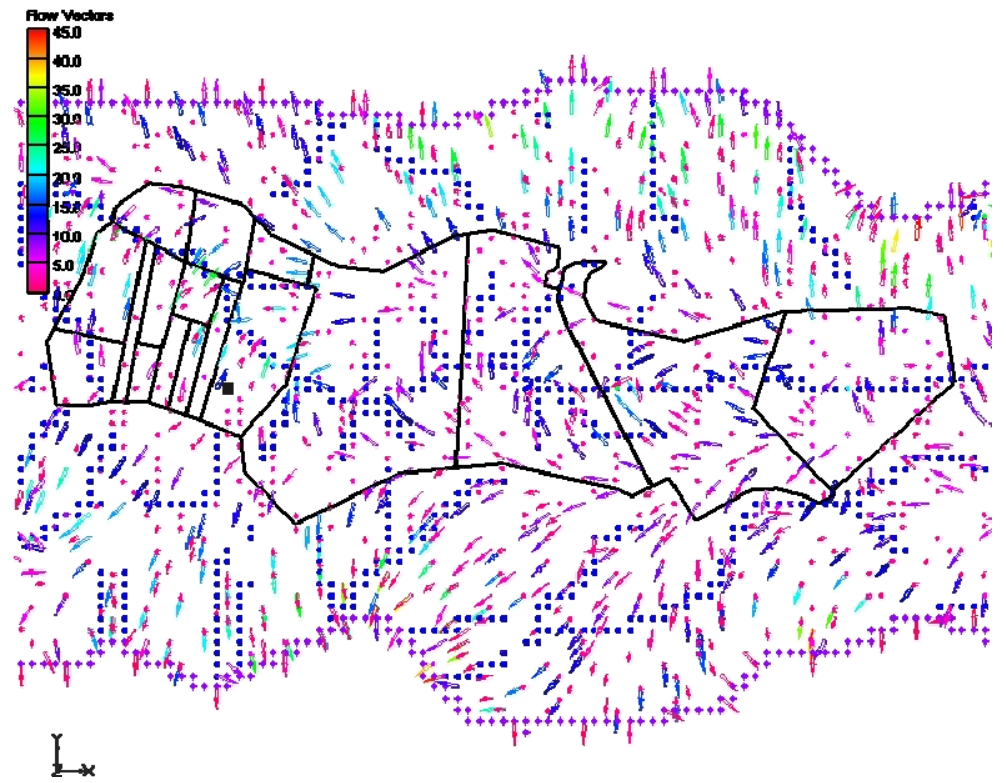

Figure 4: Intensity and direction of groundwater flow.
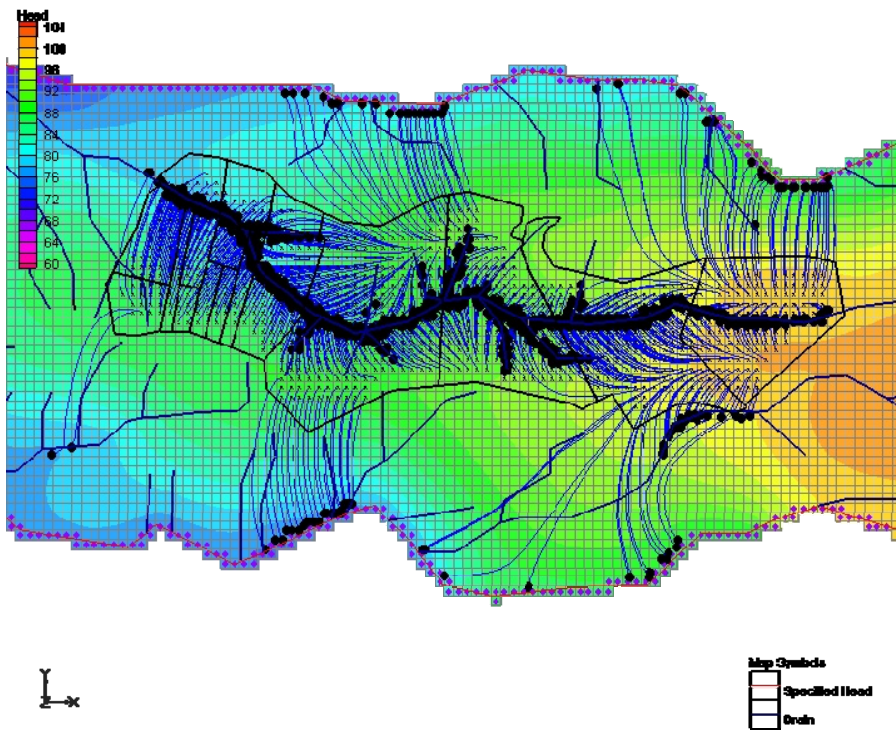

Figure 5: Groundwater particle movements. 
The water quality simulation used the MT3D model that runs in the GMS interface (http://www.modflow.com/mt3d/mt3d.html).

This model simulates mass transport in complex hydrogeological environments. This model was used to evaluate the effects (in terms of nitrates) on the vadose zone and aquifers of irrigating a variety of crops which used different fertilizers applied according to different regimens.

\section{Decision models and results}

The decision models developed allow the information derived from applying the above-described models to be used coherently and systematically. They take into account the procedures and information produced by the simulation models mentioned, after applying them to the farmland under study. Simulations were performed to show the behaviour of the farmland for the period 2007/2015 in terms of nitrogen use/uptake by the soil/final NO3- value resulting from possible scenarios of crop rotation implemented in each plot. Two decision models were constructed: the first applies to decisions that only take into account the quality indicators in the latest growing period (2015); the second model applies to decisions relating to crops in each plot, changing from period to period. The quality indicator chosen for the decision process relates to the amount of residual NO3-in the soil throughout and at the end of the vegetative life cycle.

\subsection{Decision model 1}

The formulation of the first decision model is set out below. It makes it possible to establish which of various simulated crops (maize, olive trees, honeydew melons, tomatoes and cantaloupe melons) is best suited to each of the plots of farmland. The objective function of the model is given by:

$$
\operatorname{Min} \sum_{i} \sum_{j} a_{i j} y_{i j}
$$

in which $a_{i j}$ represents the response in terms of $\mathrm{NO}_{3}$ - from plot $i$ to the growing of crop $j$ and $y_{i j}$ is a binary variable which takes the value one if crop $j$ is grown in plot $i$ and zero otherwise.

This objective is subject to a set of constraints. The first constraint represents the principle that only one crop can be grown on each plot:

$$
\sum_{i} y_{i j}=1, \forall j
$$

The second constraint expresses the principle that all the available crops should be grown:

$$
\sum_{j} y_{i j}=1, \forall i
$$

The next constraint expresses the limit, in average terms, which can be imposed on the cultivation as a result of applying fertilizer: 
94 Sustainable Irrigation Management, Technologies and Policies III

$$
\frac{\sum_{i} \sum_{j} a_{i j} y_{i j}}{N P} \leq \text { NO3med }_{\max }
$$

in which $N P$ is the number of plots and $N O 3$ med $_{\text {max }}$ is the maximum amount of $\mathrm{NO}_{3}$ - allowed on the farmland.

The variables $y_{i j}$ can only take the value zero or one.

$$
y_{i j} \in\{0,1\}
$$

The application of this model to the farmland being studied indicates the following crop distribution to minimise the residual amount of $\mathrm{NO}_{3}$ :

\begin{tabular}{cc} 
Plot & Crop \\
\hline P1 & Maize \\
P2 & Olives \\
P3 & Honeydew melons \\
P4 & Tomatoes \\
P5 & Cantaloupe melons
\end{tabular}

\subsection{Decision model 2}

The use of the second decision model, whose formulation is set out below, makes it possible to establish which of various simulated crops is best suited to each of the plots of farmland throughout the operating period of the farm. The objective function of the model is given by:

$$
\operatorname{Min} \sum_{i} \sum_{j} \sum_{k} a_{i j k} y_{i j k}
$$

in which $a_{i j k}$ represents the response in terms of $\mathrm{NO}_{3}$-from plot $i$ to growing crop $j$ in period $k$ and $\mathrm{y}_{i j k}$ is a binary variable that takes the value one if crop $j$ is grown in plot $i$ in period $k$ and value zero otherwise.

This objective is subject to a set of constraints. The first constraint represents the principle that only one crop, $j$, can be grown on each plot $i$ in each period $k$ :

$$
\sum_{i} y_{i j k}=1, \forall j, k
$$

The second constraint expresses the principle that all the available crops (maize, olives, honeydew melons, tomatoes and cantaloupe melons) must be grown, each in its own plot) in any period, $k$. 


$$
\sum_{j} y_{i j k}=1, \forall i, k
$$

The next constraint expresses the limit, in average terms, which can be imposed on the cultivation as a result of applying fertilizer:

$$
\frac{\sum_{i} \sum_{j} \sum_{k} a_{i j k} y_{i j k}}{N P^{*} N T} \leq \text { NO3med }_{\max }
$$

in which $N P$ is the number of plots and $N T$ is the number of growing periods.

In addition, this model allows a constraint to be considered regarding the limit that can be imposed on cultivation as a result of applying fertilizer, taking each plot individually, in each growing period:

$$
\frac{\sum_{j} \sum_{k} a_{i j k} y_{i j k}}{N T} \leq N O 3 \text { medpar }_{\max }, \forall i
$$

in which $\mathrm{NO}_{3 \text { medpar }}$ max represents the maximum average limit of $\mathrm{NO}_{3}$-per plot, which can be imposed as a result of applying fertilizer; another constraint on the average value for the farmland in each growing period:

$$
\frac{\sum_{i} \sum_{j} a_{i j k} y_{i j k}}{N T} \leq N O 3 \text { medanual }_{\max }, \forall k
$$

in which $\mathrm{NO}$ medanual $\mathrm{max}_{\text {max }}$ represents the maximum average limit of $\mathrm{NO}_{3}$ - in each period on the farm, which can be imposed as a result of applying fertilizer.

The variables $y_{i j}$ can only take the value zero or one.

$$
y_{i j k} \in\{0,1\}
$$

The resolution of this model, taking equal values for the limits $N O 3$ med $_{\text {max }}$, NO3medpar $_{\max }$ and NO3medanual max $_{\text {makes }}$ it possible to determine the optimum distribution of crops per plot over all the growing periods, as shown in Table 1 .

A detailed analysis of the problem leads to the conclusion that the limit value of NO3medparmax is the most restrictive. If a limit 35\% higher than the others is used it is possible to get a global value for the objective function that is better than that obtained previously, with the corresponding distribution of crops, per plot and per period, being that shown in Table 2 . 


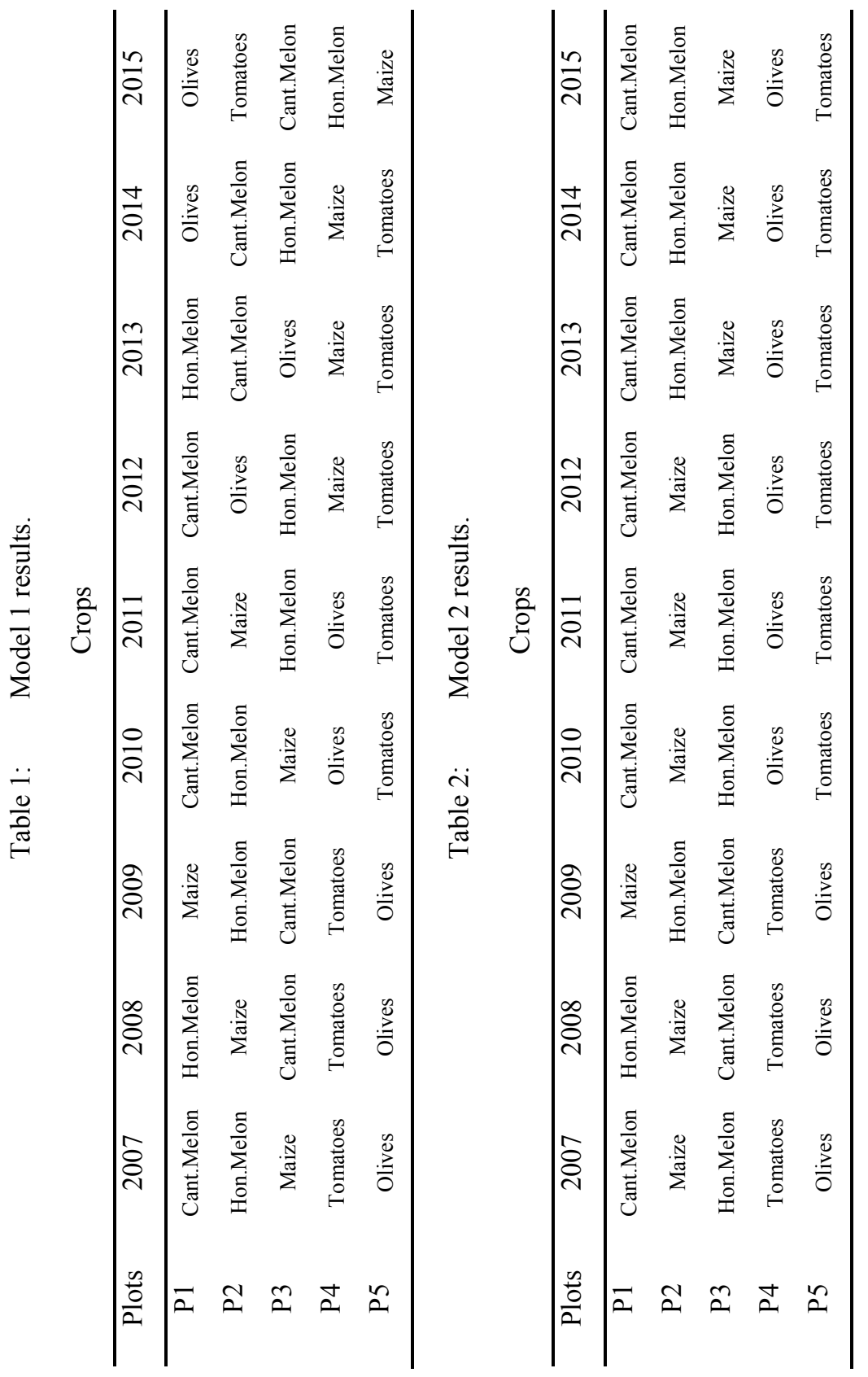




\section{Conclusions}

Sustainable land use and agricultural production practices are challenging when it comes to implementing the Water Framework Directive. In fact, diffuse pollution caused by agricultural practices is a major environmental problem. Therefore, it is very important to define technically sound measures to achieve good practices. Decision models can play an important role here. The decision models presented are very promising since they allow the definition of land use and farming practices that can minimize the effects of diffuse pollution in aquifers in order to comply with the limits set by the applicable legislation.

\section{Acknowledgement}

The authors gratefully acknowledge support received from the Fundação para a Ciência e a Tecnologia through grant POCTI/AGR/57719/2004.

\section{References}

[1] Gorantiwar, S.D, Smout, I.K. (2005), "Multilevel approach for optimizing land and water resources and irrigation deliveries for tertiary units in large irrigation schemes. I: Application", J. Irrig. Drain. Eng., 131(3), pp. 264 272.

[2] Kumar, D.N., Raju, K.S., Ashok, B. (2006), "Optimal Reservoir operation for irrigation of multiple crops using genetic algorithms", J. Irrig. Drain. Eng., 132(2), pp. 123-129.

[3] Leitão, T.E., Laranjeira, I., Oliveira, L., Paralta E., Lobo Ferreira, J.P., Cunha, M.C. and Terceiro, P. (2009), "Metodologias para um melhor planeamento e gestão do uso do solo agrícola atendendo à vulnerabilidade dos aquíferos à poluição difusa", Relatório Final. Relatório 301/2009-NAS, $206 \mathrm{pp}$.

[4] Mannocchi, F., Todisco, F. (2006), "Optimal reservoir operations for irrigation using a three spatial scales approach", J. Irrig. Drain. Eng., 132(2), pp. 130-206.

[5] Marques, F.M., Lund, J.R., Howitt, R.E. (2005), "Modelling irrigated agricultural production and water use decisions under water supply uncertainty", Water Resour. Res., 41(3), W08423.

[6] Smout, I.K., Gorantiwar, S.D. (2005), "Multilevel approach for optimizing land and water resources and irrigation deliveries for tertiary units in large irrigation schemes. I: Method", J. Irrig. Drain. Eng., 131(3), pp. 254-263. 